\title{
REPRESENTAÇÃO CULTURAL NA TRADUÇÃO PARA O INGLÊS DA OBRA DE JORGE AMADO, GABRIELA, CRAVO E CANELA
}

\author{
CULTURAL REPRESENTATION IN THE TRANSLATION TO ENGLISH OF JORGE \\ AMADO'S GABRIELA, CRAVO E CANELA
}

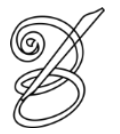 \\ Sheyla Mayra Araujo SOUSA ${ }^{1}$ \\ Mestranda em Linguagem e Ensino (CAPES) \\ Universidade Federal de Campina Grande (UFCG) \\ Campina Grande, Paraíba, Brasil \\ sheyla.mayra@hotmail.com \\ Sinara de Oliveira BRANCO ${ }^{2}$ \\ Doutorado em Letras \\ Professora Adjunta na Universidade Federal de Campina Grande (UFCG) \\ Campina Grande, Paraíba, Brasil \\ sinarabranco@gmail.com
}

Resumo: A formação e representação de identidades nacionais acontecem, geralmente, através de como as histórias das nações são contadas (HALL, 2005). Obras literárias têm o potencial de narrar tais histórias, e suas traduções (VENUTI, 1999) podem influenciar na formação de identidades nacionais, ao domesticar ou estrangeirizar valores linguísticos e culturais do texto. Pensando na tradução da obra brasileira de Jorge Amado, Gabriela, Cravo e Canela (1958), traduzi-la consiste em traduzir também o Brasil, já que tal obra é marcada pela representação de aspectos da cultura nacional. Essa é uma pesquisa descritiva orientada pelo produto (CHESTERMAN, 2009) e tem como objetivo refletir sobre de que forma através das estratégias de domesticação e estrangeirização de termos culturais a cultura brasileira é representada na tradução. Ao final da análise percebemos que os termos culturais ora são traduzidos pela estratégia de estrangeirização, ora pela domesticação e que esta última estratégia é utilizada quando a manutenção dos termos culturais tornaria a leitura problemática para o leitor do texto alvo que não conhece tais aspectos da cultura fonte.

Palavras-chave: Tradução. Identidade Nacional. Representação. Estratégias de Domesticação Jorge Amado.

Abstract: The formation and representation of national identities often happen through the way the nation's histories are told (HALL, 2005). Literary works have the power of telling such histories and their translations (VENUTI, 1999) can influence the formation of national identities by using domestication or foreignization in linguistic and cultural values of the text. Considering the translation of Jorge Amado's Brazilian book Gabriela, Cravo e Canela (1958), translating it is also translating Brazil, as this book represents national culture aspects. This is a descriptive research oriented by the product (CHESTERMAN, 2009) and it aims to reflect on how through the strategies of domestication and foreignization of cultural terms Brazilian culture is represented in translation. We noticed that cultural terms are translated either through foreignization and domestication and the latter strategy is used when the maintenance of cultural terms would turn the reading problematic for the reader of the target text who doesn't know such aspects of the source culture.

Keywords: National identity. Representation. Translation. Jorge Amado. Translation Strategies.

SOUSA, BRANCO. Representação cultural na tradução para o inglês da obra de Jorge Amado, Gabriela, cravo e canela

Belas Infiéis, v. 4, n. 3, p. 69-81, 2015. 


\section{Representação cultural}

eralmente, ao fazermos uma descrição de nós mesmos, afirmamos pertencer a uma
identidade nacional, negando outras identidades nacionais. Por exemplo, ao afirmar
sermos brasileiros, negamos que somos ingleses, argentinos ou espanhóis, como se o fato de nos identificarmos como brasileiros fosse suficiente para definir quem, de fato, somos. Do mesmo modo, ao nos identificarmos como brasileiros e nordestinos, negamos que somos de qualquer outra região do Brasil.

Hall afirma que "as identidades nacionais não são coisas com as quais nós nascemos, mas são formadas e transformadas no interior da representação" (HALL, 2005, p. 48), assim, a ideia de que brasileiro gosta de futebol e carnaval, por exemplo, constitui mais uma representação do que, de fato, é a realidade.

Uma identidade nacional é representada por diversas características, muitas das quais podem não ser, de fato, verdadeiras ou aplicáveis para todos. Hall (2005, p. 49) afirma que "as pessoas não são apenas cidadãos/ãs legais de uma nação; elas participam da ideia da nação tal como representada em sua cultura nacional", ou seja, participamos da representação de uma 70 nação porque estamos inseridos nela. Assim, o que vem a nossa mente quando falamos sobre ser brasileiro não necessariamente se aplica a todas as pessoas que nasceram no Brasil, mas todas as pessoas que se afirmam brasileiras fazem parte, inevitavelmente, dessa representação.

Os principais fatores que influenciam no surgimento de culturas nacionais são as histórias que são narradas sobre as nações, e como elas são narradas, sejam elas verdadeiras ou não. Percebemos a cultura nacional como um discurso baseado em alguns fatos envolvendo tal nação, sendo "um modo de construir sentidos que influencia e organiza tanto nossas ações quanto a concepção que temos de nós mesmos” (HALL, 2005, p. 50). Assim, aquilo que constitui nosso imaginário acerca de uma cultura ou nacionalidade geralmente é baseado em um discurso homogeneizador. Não percebemos ou consideramos a pluralidade que é própria de cada nação e cultura.

Uma nação geralmente é composta por povos de diferentes línguas, raças, religiões, costumes e ideologias que, de certa forma, são apagados para dar lugar a uma representação unificada e homogênea chamada por Hall de "comunidade simbólica" (2005, p. 49). A comunidade simbólica tem o poder de criar um sentimento de identidade e lealdade entre as pessoas que a constituem.

$\overline{\text { SOUSA, BRANCO. Representação cultural na tradução para o inglês da obra de Jorge Amado, Gabriela, cravo }}$ e canela

Belas Infiéis, v. 4, n. 3, p. 69-81, 2015. 
Dentre as formas pelas quais as histórias da nação são narradas, Hall (2005, p. 52-56) destaca: (1) a narrativa tal como é contada, representando as experiências da nação no decorrer do tempo; (2) a forma como as origens e tradições da nação são, de certa forma, imortalizadas: mesmo que o tempo tenha mudado o contexto, as supostas origens daquele povo não são esquecidas; (3) há também a invenção da tradição, pois muitas das histórias antigas de uma nação podem ser inventadas, contadas e recontadas tantas vezes que ganham validade para a sociedade; (4) Hall explica também a existência do mito fundacional, em que as nações, algumas vezes, localizam sua tradição em realidades tão antigas que a mesma acaba não fazendo mais sentido; e, por último, (5) o autor destaca que a identidade nacional é, às vezes, baseada em um povo puro, como se não houvesse diferenças entre as pessoas que constituem tal nação.

Se considerarmos a tradução como uma forma de narrativa das histórias de uma nação, podemos afirmar que tal atividade pode levar e criar representações de uma cultura para outros povos. Calvo (2010, p. 5) afirma que "a tradução exerce um papel inegável na formação de culturas, de identidades nacionais "3" (CALVO, 2010, p. 5). A tradução fortalece e divulga as representações das identidades nacionais. Assim, ao ter acesso à tradução de uma obra literária, por exemplo, o leitor, muitas vezes, se depara com a representação de uma cultura desconhecida. Nesse contato, o leitor percebe na outra cultura as diferenças e semelhanças com a sua própria, o que de início pode causar estranhamento, mas que constitui um processo enriquecedor para aquele indivíduo: ao conhecer a cultura do outro, o leitor da tradução reflete também sobre a sua própria cultura.

Venuti (1999) também percebe a tradução como ferramenta que divulga representações nacionais. O autor afirma que a tradução pode ser uma das formas pelas quais a formação de identidades culturais acontece. Ela pode criar e divulgar a representação de um povo para outras culturas. Isso pode acontecer devido às diferenças entre as culturas; alguns aspectos não existem na outra cultura, e o tradutor opta por modificá-los no texto. Assim, o texto literário, ao constituir uma das formas pelas quais a identidade nacional é narrada, cria uma representação de determinada cultura, e sua tradução, por sua vez, divulga tal representação para outros contextos e pode, também, vir a modificar tal representação. Assim, o acesso a uma tradução propicia o contato com a cultura do outro, mas tal acesso pode também levar o leitor a um contato com uma representação distorcida ou estereotipada da outra cultura.

$\overline{\text { SOUSA, BRANCO. Representação cultural na tradução para o inglês da obra de Jorge Amado, Gabriela, cravo }}$ e canela

Belas Infiéis, v. 4, n. 3, p. 69-81, 2015. 
Gabriela, Cravo e Canela de Jorge Amado (1912-2001) constitui obra literária que representa aspectos característicos da cultura brasileira, através da descrição do cenário da pequena cidade litorânea de Ilhéus, no sul da Bahia, que é pano de fundo da história; das personagens, como a sertaneja Gabriela, o carioca Mundinho Falcão, os coronéis, os padres e as moças dos bordéis da cidade, tipos característicos da representação do brasileiro nesta obra de Amado; assim como a descrição de seus costumes: as festividades, crenças religiosas, alimentação e outros. Toda a narrativa cria uma representação da cultura brasileira da época em que a história é narrada e sua tradução pode divulgar esse Brasil regional de Jorge Amado para culturas de língua inglesa.

Obra mais traduzida do autor", Gabriela foi a primeira obra da chamada "segunda fase" da escrita de Jorge Amado, que antes se dedicava mais a escrever sobre aspectos de cunho social e político. Nesse segundo momento, o autor se dedica aos romances regionalistas, em que não deixa de retratar problemas sociais. Sua obra é também marcada por uma série de crônicas de costumes da época e personagens tipicamente brasileiros por meio dos quais o autor contribui para a formação da representação brasileira.

A obra estudada foi escrita no ano de 1958 e narra o romance entre o sírio Nacib, dono de um bar, e a sertaneja Gabriela, que vai para a cidade em busca de uma vida melhor e menos sofrida que a do sertão. A história se passa na cidade litorânea de Ilhéus, no sul da Bahia, no ano de 1925. Na época, Ilhéus era uma cidade de costumes patriarcais, machistas e autoritários e passava por uma fase de transição, de mudanças sociais, entre o declínio dos coronéis que comandavam a cidade, da conscientização política da sociedade e da percepção feminina quanto ao seu poder de escolha sobre a própria vida. Gabriela, de certa forma, representa as mudanças vividas na cidade de Ilhéus, por ser uma mulher dona de si, que não teme fazer o que gosta e o que sente vontade, apesar dos costumes e ideologias da época.

Ao longo da obra, Jorge Amado leva o leitor a passear pela cidade de Ilhéus da década de 1920, a conhecer os personagens tipicamente brasileiros, assim como a conhecer os costumes e tradições da época. Consideramos que a tradução de obras literárias pode influenciar na divulgação das representações culturais de um povo, assim, a tradução de Gabriela, Cravo e Canela leva para outras culturas a representação do aspecto cultural brasileiro construído pelo autor. A seguir, discutimos como a tradução pode influenciar na representação cultural de uma nação. 


\section{Representação cultural na tradução}

Considerando a literatura como uma das formas pelas quais a representação cultural de uma nação acontece e levando em conta a tradução como uma ferramenta para o compartilhamento de tais narrativas, a tradução tem o poder de leva-la para povos de diferentes línguas e culturas, difundindo a representação da identidade cultural de uma nação.

Obras literárias podem criar representações de uma nação, ao tratar de aspectos culturais do seu contexto de origem, como é o caso de Gabriela, Cravo e Canela, que representa a cultura brasileira e baiana através da descrição de fatos, personagens, costumes e tradições. Consideramos que a tradução de obras literárias como a estudada no presente artigo proporciona a difusão do contexto explícito na obra para outras culturas, no caso estudado, culturas de língua inglesa, levando, assim, uma representação de nossa nacionalidade para leitores do livro traduzido.

Na obra estudada, Jorge Amado descreve situações específicas da cultura brasileira por meio do uso de termos culturais. Esses termos são entendidos aqui como palavras ou expressões que representam costumes, lugares, práticas religiosas, personagens folclóricos, danças, alimentos e bebidas, sendo tais termos de origem brasileira ou incorporados a esta língua e cultura. A manutenção dos termos culturais pode provocar estranhamento no leitor da tradução, pois representam, em sua maioria, realidades desconhecidas pelas culturas de língua inglesa. Esta constitui uma situação em que os tradutores da obra devem refletir acerca do que pretendem e consideram importante reproduzir na obra traduzida, e se sua intenção é causar, de fato, estranhamento quanto a determinadas realidades representadas pelos termos culturais.

Diante da ideia de que a tradução pode influenciar na formação de identidades nacionais e da afirmação de Lefevere (1992) de que "uma língua é a expressão de uma cultura, por isso muitas palavras de referida língua estão conectadas com essa cultura, e por isso, também criam muita dificuldade quando precisam ser transferidas em sua totalidade para outra língua”, o conhecimento da cultura do texto-alvo (TA) e do texto-fonte (TF) é necessário ao tradutor, pois esse conhecimento influencia nas escolhas tradutórias que reconstroem o produto em outra cultura.

Venuti menciona que a tradução é geralmente vista com desconfiança, porque registra nos textos "valores linguísticos e culturais que são inteligíveis para constituintes domésticos específicos" 5 " (VENUTI, 1999, p. 67), em outras palavras, traços culturais e linguísticos da 
cultura alvo podem ser impressos na tradução para que a mesma atinja mais facilmente ou de uma forma pretendida, o leitor do texto traduzido, como no exemplo abaixo:

Tabela 1. Tabela 1- Tradução do termo cultural "jagunço"

\begin{tabular}{|c|c|}
\hline Portu & lês \\
\hline $\begin{array}{l}\text { Passavam ainda muitos } \\
\text { homens calçados de botas, } \\
\text { exibindor revólveres, } \\
\text { estouravam ainda facilmente } \\
\text { arruaças nas ruas de canto, } \\
\text { jagunços conhecidos }\end{array}$ & $\begin{array}{l}\text { Men wearing boots and } \\
\text { carrying guns still were } \\
\text { seen; fights broke out in } \\
\text { alleys; known assassins } \\
\text { pushed people around in } \\
\text { cheap bars and }\end{array}$ \\
\hline $\begin{array}{l}\text { arrotavam valentias nos } \\
\text { botequins baratos, de quando } \\
\text { em vez um assassinato era } \\
\text { cometido em plena rua. p. } 10\end{array}$ & $\begin{array}{l}\text { occasionally murdered } \\
\text { someone right out in the } \\
\text { street. p. } 20\end{array}$ \\
\hline
\end{tabular}

Na Tabela 1, o termo cultural "jagunços" que se refere ao indivíduo que manipula uma arma de defesa, cangaceiro, valentão assalariado (CUNHA, 2013, p. 371), é traduzido por assassins, assassinos em uma tradução literal para o português. Se o tradutor mantivesse no 74 texto em inglês o termo "jagunço", provavelmente a passagem não seria compreendida pelos leitores que não conhecem o ofício por esse termo. Provavelmente por esse motivo, os tradutores usaram o termo assassins que é inteligível para os leitores da tradução, traduzindo também, tanto quanto possível, a situação descrita na obra original.

O tradutor tem duas opções, segundo Venuti, domesticar ou estrangeirizar aspectos do texto. A domesticação é um método em que existe "uma redução etnocêntrica do texto traduzido para os valores culturais da língua alvo, levando o autor de volta para casa" (VENUTI, 1995, p. 20), o exemplo acima consiste no uso da estratégia de domesticação. Essa estratégia costuma ocorrer com traduções de obras para a língua inglesa. Para o autor, essa não constitui uma estratégia ética, pois apaga traços culturais e linguísticos da obra original, dando lugar a características da cultura alvo. Muitas vezes, porém, essa estratégia é utilizada com o propósito de que a leitura seja facilitada para o leitor da tradução, que não conhece aspectos específicos do contexto original.

Consideramos que a domesticação é necessária na tradução, pois há situações e contextos que são ininteligíveis para outras culturas e precisam da reflexão do tradutor sobre como comunicar determinada situação para o contexto do texto traduzido. Porém, é importante prezar para que não se perca a identidade da cultura fonte, no caso estudado, da

SOUSA, BRANCO. Representação cultural na tradução para o inglês da obra de Jorge Amado, Gabriela, cravo e canela

Belas Infiéis, v. 4, n. 3, p. 69-81, 2015. 
cultura brasileira. Há uma ética que precisa ser respeitada para que a tradução e o contexto retratado na obra não se percam nas mudanças que o tradutor precisa fazer.

A estratégia de estrangeirização, mencionada por Venuti (1995), constitui o caminho contrário da domesticação ao manter no texto valores linguísticos e culturais do TF. A estrangeirização "significa levar o leitor para a cultura estrangeira, fazendo-o ver as diferenças (culturais e linguísticas) (...). Uma estratégia de estrangeirização procura evocar uma sensação de estrangeiro ${ }^{7 \%}$ (VENUTI, 1999, p. 4). A estrangeirização proporciona ao leitor viajar ao contexto original da obra que está lendo e ter acesso, tanto quanto possível, aos aspectos culturais e linguísticos daquela cultura estrangeira. Observemos a Tabela 2:

Tabela 2 - Tradução de termos culturais referentes a danças populares

\begin{tabular}{|l|l|}
\hline \multicolumn{1}{|c|}{ Português } & \multicolumn{1}{|c|}{ Inglês } \\
\hline $\begin{array}{l}\text { Dança para ela era outra } \\
\text { coisa, um coco mexido, um } \\
\text { samba de roda, um maxixe } \\
\text { embolado. p. } 190\end{array}$ & $\begin{array}{l}\text { something else: a samba } \\
\text { ring, a fast maxixe, a lively } \\
\text { coco dance such as they did } \\
\text { in the backlands. } \text { p. } 336\end{array}$ \\
\hline
\end{tabular}

A Tabela 3 apresenta termos referentes a danças populares que a personagem Gabriela gostava de dançar: coco mexido, samba de roda e maxixe embolado. Esses termos foram traduzidos de forma estrangeirizada, levando os leitores da tradução a conhecer um pouco desse aspecto cultural brasileiro presente na obra. Acreditamos que o tradutor fez menção ao sertão em "such as they did in the backlands" para melhor situar seu leitor naquele contexto. Durante a leitura, o leitor fica sabendo que tais danças eram comuns no sertão da Bahia, onde Gabriela nasceu.

Consideramos que a visão de Venuti de que apenas a domesticação constitui uma imposição etnocêntrica à tradução parece unilateral. Impor aspectos linguísticos e culturais da obra original no processo de tradução nos parece também uma imposição etnocêntrica. É fato que existem aspectos no texto que levados à tradução proporcionariam o contato do leitor com a cultura fonte, já outros aspectos, se levados à tradução, por serem muito específicos tornariam a leitura problemática devido à falta de conhecimento por parte do leitor sobre a cultura fonte.

Como afirma Katan, "uma tradução estrangeirizada pode levar o leitor para um conjunto de valores etnocêntricos" ${ }^{8 "}$ (KATAN, 1999, p. 156). Dessa forma, a tradução estrangeirizadora, que tem uma proposta não etnocêntrica, acaba também o sendo, ao impor

SOUSA, BRANCO. Representação cultural na tradução para o inglês da obra de Jorge Amado, Gabriela, cravo e canela

Belas Infiéis, v. 4, n. 3, p. 69-81, 2015. 
que o texto traduzido apresente todos os aspectos específicos da cultura de origem para o leitor estrangeiro.

A ideia da transparência entre textos através do uso de domesticação constitui uma ilusão, uma vez que, ao ler um texto domesticado, o leitor entra em contato com uma realidade diferente daquela do TF. Isso não significa que a estrangeirização proporciona ao leitor o contato propriamente dito com a realidade expressa na obra original, mas essa estratégia evita apagar traços e valores culturais no processo de tradução, proporcionando ao leitor, sempre que possível, o conhecimento da cultura fonte e de suas peculiaridades, que a fazem diferente da cultura do leitor da tradução.

\section{A tradução de Gabriela, Cravo e Canela e suas implicações para a representação da cultura brasileira}

O interesse mercadológico geralmente é uma das razões para a realização da tradução de um texto literário. Há também o interesse que a obra alcance outras culturas. No Brasil, temos exemplos de escritores consagrados que tiveram suas obras traduzidas, como Jorge Amado, Machado de Assis, Graciliano Ramos, Clarice Lispector, Raquel de Queiroz, entre

76 outros. As traduções desses escritores levam a cultura do povo brasileiro para os falantes das línguas em que foram traduzidas, difundindo o contexto cultural do nosso país para várias partes do mundo.

Jorge Amado, um dos escritores com o maior número de obras traduzidas, escrevia sobre as características de nosso país e de nossa cultura, muitas vezes servindo-se de vocábulos regionais para expressar determinados conceitos. Arcoverde (2014, p. 249) referese a Jorge Amado como "um escritor coloquial por excelência, embora dominasse a variante culta". A afirmação da autora se baseia no uso frequente de expressões populares nas obras do escritor, como por exemplo, o uso de termos culturais.

Gabriela, Cravo e Canela é uma obra literária que representa a cultura brasileira e foi traduzida para diversos idiomas, podendo levar o contexto cultural brasileiro para vários países. Ao levar em conta o poder que a tradução tem de influenciar na formação e representação de identidades culturais, convém refletir sobre a forma pela qual a tradução da obra para a língua inglesa, realizada em 1962, por Grossman e Taylor, traduziu o Brasil regional de Jorge Amado para culturas falantes dessa língua.

Como mencionado anteriormente, Jorge Amado fazia uso de expressões regionais ao escrever suas obras. Consideramos que a análise da tradução dos termos culturais por meio

SOUSA, BRANCO. Representação cultural na tradução para o inglês da obra de Jorge Amado, Gabriela, cravo e canela

Belas Infiéis, v. 4, n. 3, p. 69-81, 2015. 
das estratégias de domesticação e estrangeirização pode nos auxiliar na análise da tradução do Brasil regional de Jorge Amado.

Vejamos o seguinte exemplo da obra escrita em português e sua tradução na tabela 3:

Tabela 3 - Tradução do termo cultural "galinha de cabidela"

\begin{tabular}{|l|l|}
\hline \multicolumn{1}{|c|}{ Português } & \multicolumn{1}{|c|}{ Inglês } \\
\hline Oh! - exclamava ante o aroma a exalar-se da & "Ah! he exclaimed, as he inhaled the aroma \\
galinha de cabidela, da carne de sol assada, & from the chicken stew, the jerked beef, the \\
do arroz, do feijão, do doce de banana em & rice, the beans, and the banana compote." \\
rodinhas. (AMADO, 1958, p. 84). & (TAYLOR \& GROSSMAN., 1962, p. 147). \\
\hline
\end{tabular}

O termo "galinha de cabidela" representa um prato que não é comum nos países de língua inglesa e tem como principal ingrediente o sangue da galinha acrescido de vinagre. Segundo Lopes (2010) ${ }^{9}$, em matéria no jornal Estado de São Paulo, herdamos esse prato dos portugueses, porém há controvérsias a respeito de sua origem. Sabemos que tal iguaria pode causar no mínimo estranhamento para povos que não têm o costume de comer um prato que utiliza sangue de animal como um de seus ingredientes. Chicken stew, por sua vez, termo utilizado na obra traduzida, pode ser traduzido literalmente para o português como galinha cozida, prato também comum na cultura brasileira.

Em pesquisas em dicionários impressos não encontramos o termo "galinha de cabidela". Já em ferramentas de tradução online, percebemos que o termo é traduzido como chicken stew, chicken giblets, e cabidela chicken. O primeiro termo refere-se a uma galinha cozida, tal como conhecemos no Brasil; o segundo refere-se ao cozimento do miúdo da galinha, ou seja, das partes internas consideradas como sobras do animal; já o terceiro termo refere-se, de fato, ao prato conhecido no Brasil como galinha de cabidela.

Para Corrêa (2003, p. 96) "seria impossível que no decorrer da narrativa o leitor conseguisse vivenciar a experiência sensorial que os conhecedores da realidade extralinguística daquela palavra". Tal afirmação justifica a atitude dos tradutores em fazer uso de domesticação e substituir o termo "galinha de cabidela" por um que representa uma realidade conhecida pelos leitores do texto traduzido, e assim não causar estranhamento ao leitor da tradução.

Percebemos aqui a questão da representação cultural. Como afirma Venuti (1999), as traduções tendem a estereotipar as culturas estrangeiras. Nesse caso, o prato característico da 
culinária brasileira é apagado dando lugar a um prato mais comum para a cultura alvo. Tal atitude, ao modificar aspectos do texto por meio da domesticação, se usada com grande frequência, pode vir a descaracterizar, de fato, aspectos da nossa cultura.

Porém, é importante ressaltar como a domesticação pode auxiliar o tradutor a transferir uma mensagem que antes não seria inteligível, para o público alvo. Mesmo havendo mudança no sentido da passagem, a mensagem é transferida para o texto em inglês da forma mais adequada que os tradutores encontram para aquela situação.

Agora observemos o exemplo da tabela 4:

Tabela 4 - Tradução dos termos culturais referentes a personagens religiosos

\begin{tabular}{|l|l|}
\hline \multicolumn{1}{|c|}{ Português } & \multicolumn{1}{|c|}{ Inglês } \\
\hline Seu Nilo se transformava, era todos os santos, & Nilo was transformed into all the gods - Ogun \\
era Ogun e Xangô, Oxossi e Omolu, era Oxalá & and Xango, Oxossi and Omulu; for Dora he was \\
para Dora. Chamava Gabriela de Yemanjá, & the great god Oxala. Gabriela was Yemanja, \\
dela nasciam as águas, o rio Cachoeira e o mar & goddess of the sea. p. 382 \\
de Ilhéus, as fontes nas pedras. p. 216 & \\
\hline
\end{tabular}

Percebemos o uso de estrangeirização na passagem acima. Foram mantidos os termos culturais referentes aos orixás, santos do Candomblé, religião de origem africana que tem muitos seguidores no Brasil. Jorge Amado fazia referência ao Candomblé em muitas de suas obras ${ }^{10}$ e era também membro da religião.

Para Venuti (1995, p. 20) a estrangeirização é uma estratégia que procura conter a violência etnocêntrica que a tradução pode impor a determinadas culturas. Para o autor, procurar representar o contexto cultural e linguístico da obra a ser traduzida para a língua inglesa é uma maneira de resistir à supervalorização de culturas de língua inglesa e ao consequente apagamento de outras culturas, no caso aqui estudado, a cultura brasileira. É o que parece ter acontecido na passagem acima, talvez por ser característica marcante nos romances do autor, e religião popular no Brasil, os tradutores decidiram manter as referências ao Candomblé na obra, permitindo aos leitores da tradução uma aproximação com as personagens que constituem a religião afrodescendente e o contato com esta característica importante da cultura brasileira. 


\section{Conclusão}

A literatura é uma das formas de narrar histórias de uma nação, participando das formas de representação cultural. É importante ressaltar que até mesmo a literatura produzida em um país pode criar estereótipos daquela cultura, e a tradução, ao divulgar essas narrativas para outras nações, pode acabar por modificar situações específicas da cultura de origem, para que o contexto seja entendido mais facilmente pelo leitor estrangeiro. Porém, essa atitude pode criar representações culturais acerca de aspectos como religião, crenças e costumes da cultura de origem, que divulgam como sendo verdadeiros tais aspectos, formando novos estereótipos.

Percebemos que o uso de ambas as estratégias (domesticação e estrangeirização) na tradução exerce papel importante na representação cultural brasileira. Tanto a domesticação como a estrangeirização podem apagar, modificar ou manter aspectos culturais brasileiros. Analisá-los com cautela, pensando na recepção do leitor da obra traduzida e na manutenção, tanto quanto possível, da mensagem, é a atitude que buscamos ao analisar a tradução da obra.

Consideramos que o uso dessas estratégias influencia na representação cultural brasileira para os leitores do texto traduzido. Escolhas tradutórias são reflexos do que os tradutores ou o mercado consideram que deve ser ou não levado para outra cultura alvo. $\mathrm{O}$ tradutor atua como um mediador cultural (KATAN, 1999), ao estabelecer a comunicação entre povos distintos e tem o poder de criar representações culturais em seu trabalho, precisando, portanto, agir de forma ética, respeitando, tanto quanto possível, o leitor da tradução, o autor do original e a mensagem.

Consideramos que a estrangeirização deve ser utilizada quando possível pelo tradutor, pois "uma tradução perde sua especificidade se ela apaga o desvio existente entre as duas línguas/culturas" (FERREIRA, 2011, p. 36). Porém, o uso da domesticação se faz necessário e adequado em situações específicas em que a tradução estrangeirizada de determinado contexto não constitui a melhor escolha pois tornaria a leitura problemática para o leitor.

Concebemos, por fim, que as duas estratégias devem ser usadas de forma ética, considerando questões linguístico-culturais representadas na obra original e o leitor da tradução, que desconhece tal contexto. Assim, o uso de domesticação e estrangeirização pode ser realizado de forma vantajosa para a manutenção do sentido do texto e para a experiência do leitor. 


\section{REFERÊNCIAS BIBLIOGRÁFICAS}

AMADO, J. Gabriela, cravo e canela. São Paulo: Martins, 1958.

AMADO, J. Gabriela, clove and cinnamon. Tradução de William L. Grossman e James L. Taylor. New York: Crest book, 1962.

ARCOVERDE, M.D.L. O querer-dizer de Jorge Amado no viés popular. In: FIGUEIREDO, E.L.L.; GERMANO, P.G.; SWARKANAR, S. (Org). Nova leitura crítica de Jorge Amado.Campina Grande: Eduepb, 2014. p. 249-266.

CALVO, M. M. Translation and cross-cultural communication. In: CALVO, M. M.; GÓMEZ, C. B. Translation and cultural identity: selected essays on translation and crosscultural communication. Newcastle: Cambridge Scholars, 2010.

CHESTERMAN, A. The name and nature of translator studies. Hermes, Aarhus. p. 13-22, 2009. Disponível em: <http://download1.hermes.asb.dk/archive/download/Hermes-42-2chesterman_net.pdf>. Acesso em: 05/11/2015.

CORRÊEA, R. H. M. A. A tradução dos termos culturais extra-linguísticos: Jorge Amado traduzido. TradTerm, São Paulo, v. 9, p. 93-137, 2003. Disponível em: <http://myrtus.uspnet.usp.br/tradterm/site/images/revistas/v09n1/v09n1a09.pdf> Acesso em: 27/04/2015.

CUNHA, A. G. Dicionário etimológico da língua portuguesa. 4. ed. Rio de Janeiro: Lexicon, 2010 .

DIAS LOPES, J. A. V. Ascenção e queda da galinha de cabidela. [Internet]. São Paulo: Estadão; 2010. Disponível em: <http://www.estadao.com.br/noticias/geral,ascensao-e-quedada-galinha-de-cabidela,4002> Acesso em: 11/06/2015.

FERREIRA, A. M. A. A tradução como prática mestiça: um modelo possível para um ethos contemporâneo. In: BELL-SANTOS, C. A.; HATJE-FAGGION, V.; ROSCOE-BESSA, C.; SOUSA, G. H. P. (Org.). Tradução e cultura. Rio de Janeiro: 7 letras, 2011. p. 23-37.

HALL, S. A identidade cultural na pós-modernidade. 10. ed. Rio de Janeiro: DP\&A editora, 2005 .

KATAN, D. Translating cultures: an introduction for translators, interpreters and mediators. Manchester: St. Jerome, 1999.

LEFEVERE, A. Translation, rewriting, and the manipulation of the literary fame. London: Routledge, 1992.

PRANDI, R. Religião e sincretismo em Jorge Amado. In: SCHWARCZ, L. M.; GOLDSTEIN, I. S. (Org.). Caderno de leituras: o universo de Jorge Amado. Companhia das letras. $\quad$ p. 46-61. Disponível em: <http://www.jorgeamado.com.br/professores2/professores02.pdf> Acesso em: 27/07/2015.

$\overline{\text { SOUSA, BRANCO. Representação cultural na tradução para o inglês da obra de Jorge Amado, Gabriela, cravo }}$ e canela

Belas Infiéis, v. 4, n. 3, p. 69-81, 2015. 
VENUTI, L. The translator's invisibility: a history of translation. London/NY: Routledge, 1995.

. Translation and the formation of cultural identities. In: C. Shaffner; H. KellyHolmes. Cultural functions of translation. Clevedon: Multilingual Matters, 1995.

. The scandals of translation. London: Routledge, 1999.

\footnotetext{
${ }^{1}$ Lattes Sheyla Mayra Araujo Sousa. Disponível em: http://lattes.cnpq.br/6639728080779002

${ }^{2}$ Lattes Sinara de Oliveira Branco. Disponível em: http://lattes.cnpq.br/6023441911258549

${ }^{3}$ Translation plays an undeniable role in the shaping of cultures, of national identities (CALVO, 2010, p. 5). (tradução nossa)

${ }^{4}$ Disponível em: <http://www.jorgeamado.org.br/?page_id=148\&lang=pt\&obra=502\&start=15\#obra> Acesso em: 23/07/2015;

${ }^{5}$ Linguistic and cultural values that are intelligible to specific domestic constituencies (VENUTI, 1999, p. 67). (tradução nossa)

${ }^{6}$ A domesticating method, an ethnocentric reduction of the foreign text to target-language cultural values, bringing the author back home (VENUTI, 1995, p. 20). (tradução nossa)

${ }^{7}$ Foreignizing... means taking the reader over to the foreign culture, making him or her see the (cultural and linguistic) differences... A foreignizing strategy seeks to evoke a sense of the foreign (VENUTI, 1995, p. 4). (tradução nossa)

${ }^{8}$ A foreignized translation can lead the reader to an ethnocentric set of values (KATAN, 1999, p. 156). (tradução nossa)

9 Disponível em: <http://www.estadao.com.br/noticias/geral,ascensao-e-queda-da-galinha-de-cabidela,4002> Acesso em: 27/07/2015;

${ }^{10}$ Disponível em: <http://www.jorgeamado.com.br/professores2/05.pdf>Acesso em: 27/07/2015.
}

RECEBIDO EM: 31 de agosto de 2015

ACEITO EM: 07 de dezembro de 2015

$\overline{\text { SOUSA, BRANCO. Representação cultural na tradução para o inglês da obra de Jorge Amado, Gabriela, cravo }}$ 